\title{
Improving the clinical assessment of consciousness with advances in electrophysiological and neuroimaging techniques
}

\author{
Jodie R Gawryluk ${ }^{1,2}$, Ryan CN D'Arcy ${ }^{1,2,3}$, John F Connolly', Donald F Weaver ${ }^{5,6,7^{*}}$
}

\begin{abstract}
In clinical neurology, a comprehensive understanding of consciousness has been regarded as an abstract concept best left to philosophers. However, times are changing and the need to clinically assess consciousness is increasingly becoming a real-world, practical challenge. Current methods for evaluating altered levels of consciousness are highly reliant on either behavioural measures or anatomical imaging. While these methods have some utility, estimates of misdiagnosis are worrisome (as high as 43\%) - clearly this is a major clinical problem. The solution must involve objective, physiologically based measures that do not rely on behaviour. This paper reviews recent advances in physiologically based measures that enable better evaluation of consciousness states (coma, vegetative state, minimally conscious state, and locked in syndrome). Based on the evidence to-date, electroencephalographic and neuroimaging based assessments of consciousness provide valuable information for evaluation of residual function, formation of differential diagnoses, and estimation of prognosis.
\end{abstract}

\section{Review Introduction}

Consciousness is a poorly-defined concept, the meaning of which is more a matter of debate than an issue of certainty [1-4]. While philosophy has focused on the mind-body problem, and psychology has focused on knowledge of experience [1], remarkably little attention has been paid to the practical problems that arise from our inability to rigorously evaluate consciousness in the clinical setting. Given the myriad of common disorders that alter consciousness, the need for more sophisticated clinical assessment methods is an important and pragmatic issue.

The dilemma of assessing consciousness is also of public interest - and the public is looking towards medical science for insights. This public fascination with consciousness was well exemplified by the media attention focused upon the medical/legal/ethical problems of the Terri Schiavo and Terry Wallis cases [5]. These cases highlighted the need to assess an individual's level of

\footnotetext{
* Correspondence: Donald.Weaver@dal.ca

${ }^{5}$ Queen Elizabeth II Health Sciences Centre (Neurology), Halifax, Canada
}

consciousness beyond simply observing their behavioural status. More recently, the dramatic increase in survivable brain injuries occurring during military conflicts is also emphasizing the need for improved tools with which to assess consciousness [6,7].

Regrettably, the time-honored structural imaging techniques (computed tomography, magnetic resonance imaging) and crude behavioural assessments (Glasgow Coma Scale) that are routinely used to assess altered consciousness are inadequate. While other more sophisticated measures exist (e.g., JFK Coma Recovery Scale Revised), many of these tests rely on the observation of behaviours (e.g., motor and/or communicative responses) that may be impaired in brain injured people. Indeed, such behaviours are often decoupled from consciousness as a direct result of the brain injury. Accordingly, there is a critical need to improve the clinical evaluation of consciousness using non behavioral based, physiologically based measures. Although ignored for routine clinical application, electrophysiological measures such as evoked potentials and event-related potentials or ERPs (derived from electroencephalography, 
which measure "brain waves") address this need. In this respect, electroencephalography and related methods represent an option that provides valuable clinical insight while being more accessible than other functional imaging modalities (e.g. functional magnetic resonance imaging). This report examines the potential clinical utility of an electrophysiological approach to the assessment of consciousness. Such electrophysiological indicators of consciousness have emerged from both diagnostic and prognostic studies, which support the interplay of these two key clinical questions. Please note that this report is not intended to be an exhaustive review of the literature. Rather, we describe representative examples illustrating how the assessment of consciousness may be improved with electrophysiological as well as neuroimaging techniques.

\section{States of Consciousness}

Consciousness is a complex brain centered state of subjective experience. Although various models exist, consciousness is commonly defined by the dual aspects of wakefulness and awareness (of both the external environment and the inner self): wakefulness refers to the sub-state that permits open eyes and a degree of motor arousal (i.e. wakefulness defines the level of consciousness); awareness refers to the sub-state that enables experience of thoughts, memories, and emotions (i.e. awareness defines the content of consciousness) [8]. Although wakefulness and awareness are intimately connected - in general, one has to be awake to be aware - it is possible to identify circumstances under which they are dissociated: in complex partial seizures wakefulness can occur without awareness; in rapid eye movement sleep it is possible to be aware but not awake.

Currently, four diagnostic levels are used to describe the spectrum of disordered consciousness: coma, vegetative state, minimally conscious state, and locked-in syndrome (it should be noted that although these terms are among the most discussed and familiar, a wide range of terms exist to describe patients across the spectra used to describe consciousness - e.g., acute confusional state, amnestic state, and obtunded). While these four terms do not completely describe all patients, they provide a useful classification starting point that is widely used in the literature.

Coma (a state of deep, unarousable unconsciousness) typically follows either brainstem injury or bilateral hemispheric damage [9]. Individuals in coma have an absence of both wakefulness and awareness.

From coma, a person may transition into a vegetative state (See Figure 1) $[10,11]$. This condition is characterized by wakefulness without awareness. Vegetative people have their eyes open and retain sleep and wake cycles, yet are unaware of themselves or their surroundings; they may even spontaneously grimace, cry or smile
[8]. A vegetative state typically occurs when the brainstem is intact, but the cortex is extensively damaged $[10,12]$, although thalamic lesions are commonly reported in this condition as well $[13,14]$. Not surprisingly, the vegetative state is difficult to evaluate as an altered level of consciousness.

The concept of a minimally conscious state is a relatively new diagnostic entity. Minimally conscious state is a condition in which consciousness is severely altered but some behavioural evidence of awareness remains; i. e., wakefulness with significantly diminished awareness [15]. Evidence of awareness may be demonstrated through proper use of common objects (e.g. a comb) or through non-verbal communication. The minimally conscious state can persist indefinitely or progress to full consciousness $[15,16]$.

Another level of consciousness is locked-in syndrome, a condition associated with injury to the ventral pons $[17,18]$. Locked-in syndrome is characterized by intact wakefulness and awareness, but with quadriplegia and expressive anarthria; thus the afflicted individual has preserved consciousness, but, because of an inability to produce behavioural responses, appears to be unconscious [17]. This state typically follows an acute stage of impaired consciousness. Locked-in syndrome is unique in that patients in this disordered consciousness state have been able to relay their experiences. One prominent case of locked-in syndrome is that of Bauby, who provided a personal account of his experiences; Bauby describes witnessing discussions about his condition, while being helplessly unable to tell anyone that he was awake, aware and "really in there" [19]. His writings eloquently highlight a critical problem - the lack of effective clinical assessments for awareness/consciousness.

The seriousness of the consciousness assessment problem is demonstrated by the situation in which almost half of cases are misdiagnosed. Specifically, examination of the failings of conventional diagnostic approaches has yielded a misdiagnosis rate as high as $43 \%$ [20-22]. The Glasgow Coma Scale remains the "gold standard" for routine assessment of consciousness, but relies exclusively on behavioural responses [23,24]. Likewise the Disability Rating Scale also involves basic behavioural functions like eye opening, communication and motor response [25]. Although other measures of consciousness exist, all are based on behavioural signs of consciousness that are subjectively observed. The search for objective physiological measures of consciousness yielded electrophysiological approaches, which were soon followed by functional imaging approaches [26]. While both approaches can provide valuable information, the current paper focuses on electrophysiology as this technology is readily available across a range of 


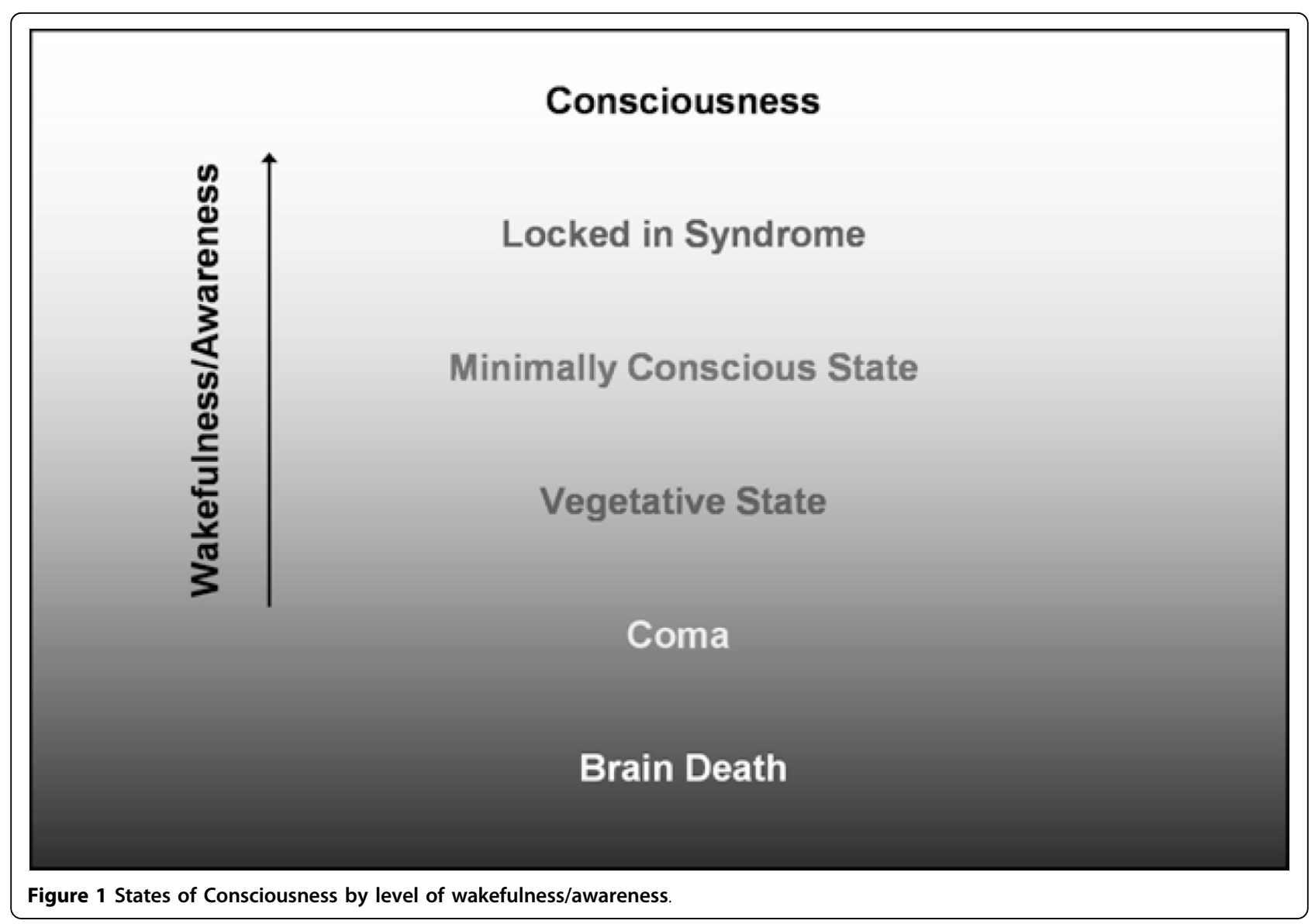

clinical settings and thus provides a practical tool for the consciousness assessment problem [27].

\section{Advances in Functional Neuroimaging}

Functional imaging (as opposed to structural imaging, which produces "brain pictures") describes the broad array of techniques used to assess brain function from a physiological perspective (as opposed to anatomical) [28]. One of the most well known approaches is functional magnetic resonance imaging [29,30]. Using functional magnetic resonance imaging, it is possible to track fluctuations in blood oxygenation in order to localize functionally active regions in the brain. When assessing consciousness, for example, functional magnetic resonance imaging has been used to examine activation differences between blocks of normal speech and reversed speech, making it possible to isolate regions involved in higher-level auditory processing [31,32].

Though less well known, electrophysiology represents a more established clinical option, in which evoked potentials and event-related potentials are derived from scalp-recorded electroencephalography. Evoked potentials and event-related potentials are responses that occur during the presentation of or in response to stimuli and provide an on-line record of information processing in the brain [33]. The term evoked potentials (EPs) generally refers to sensory processing responses, whereas, event-related potentials (ERPs) refers to perceptual and cognitive processing responses. In terms of nomenclature, both tend to be named according to their polarity and latency; thus, an N100 component is a negative-going waveform that peaks around $100 \mathrm{~ms}$ after the stimulus.

Sensory EPs are most commonly used for clinical assessment of basic sensory functions. Brainstem auditory evoked potentials (BAEPs) occur in the $10 \mathrm{~ms}$ range and are often employed in the assessment of coma. The absence of an intact brain stem response is indicative of a poor prognosis for recovery [34]. Sensory EPs also include somatosensory evoked potentials (SEPS), middle-latency auditory evoked potentials (MLAEPs), and visual EPs (VEPs) that occur in the 30 ms range and are used to evaluate primary sensory cortices. Cognitive ERPs are used to evaluate higher level functions like attention, memory, and language, which make them well-suited to assessing aspects of consciousness [35]. One of the most well known ERPs is the P300, which is elicited to an improbable or "oddball" 
stimulus that is embedded within a train of standard stimuli. (eg, auditory tones) [36-38].

ERP studies focusing on the assessment of conscious awareness have frequently examined four specific components - the N100, the mismatch negativity (MMN), the P300, and the N400 [35-39]. The N100 indexes sensory/perceptual functions during visual, auditory and somatosensory processing $[40,41]$. The MMN, a negative-going waveform occurring around 150-250 ms, has been linked to perceptual processing of deviant auditory stimuli that occurs below the level of conscious awareness [42]. The P300, which also occurs to deviant or odball stimuli, is thought to reflect higher level processing, such as immediate memory [37]. It is often known as the "Ah Hah!" response. Another important cognitive ERP component is the N400 [43,44]. The N400 is commonly observed following sentences that end with semantically inappropriate words ("He takes coffee with cream and socks"). The semantic violations can be used to assess language comprehension, by examining whether an N400 is present when comparing sentences with and without appropriate endings [45-49].

\section{Physiologically Based Evaluations of Consciousness}

Electrophysiological approaches can be used to assess consciousness (i.e. awareness) across the spectrum of pathologies associated with disordered consciousness.

\section{Coma}

BAEPs are often employed in the assessment of coma, with the absence of response being indicative of a poor prognosis [50]. Additionally, the absence of cortical components of SEPs and of MLAEPs can also be strong indicators of a poor prognosis [51,52]. Although not currently implemented for routine use, cognitive ERPs have shown promise in determining prognosis. Fischer et al. evaluated 350 comatose patients with auditory EPs and ERPs (N100 and MMN components). They found that the MMN response was the strongest predictor of functional recovery [50]. Strikingly, $88.6 \%$ of individuals with the MMN response progressed towards awakening, corresponding with other studies, which show that the MMN can predict progression towards improved levels of consciousness [34,53,54]. Furthermore, recent metaanalysis indicated that the MMN and P300 are significantly more accurate than the N100 at predicting awakening [55]. In accordance with this, another study by Fischer et al., demonstrated that a novelty P300 elicited by the subjects own name can be used to enhance the sensitivity of assessment with the MMN and thereby increase prognostic utility in comatose patients [56].

\section{Vegetative State}

Because vegetative state precludes verbal and motor responses, patients must be evaluated with alternative means, such as ERPs. Connolly et al. used cognitive ERPs in the case of man with a left temporal lobe knife wound whose ability to comprehend language was unknown (Figure 2) [47]. The task involved visual and auditory presentation of semantically appropriate and inappropriate sentences. The data from the auditory task showed a clear N400 response, indicating that awareness was intact and illustrating that cognitive ERPs can be used to assess awareness in individuals unable to communicate (Figure 3) [47].

Wijnen et al. used the MMN response to predict functional recovery in vegetative state. Ten patients were assessed with the MMN and the P300 [57]. The results indicated that larger MMN components were associated with improved signs of consciousness. Importantly, Wijnen et al. found that individuals with higher amplitudes and shorter latencies in their MMN measurement were more likely to have a higher level of consciousness two years later. Electrophysiological evaluations can be augmented by functional imaging techniques to further enhance the assessment of consciousness. For instance, functional magnetic resonance imaging and positron emission tomography studies of patients in altered levels of consciousness typically assess passive activation patterns, such as patient responses to their own name [32]. Recently, Owen et al. pursued a unique approach when evaluating a 23 year old female in a vegetative state [58]. After confirming that the patient was able to hear auditory stimuli, she was given two mental imagery tasks to assess level of awareness. She was asked to imagine playing a game of tennis and to imagine visiting all of the rooms in her home (spatial navigation imagery). Both tasks elicited activation patterns that were indistinguishable from those produced by controls (supplementary motor areas during tennis task and parahippocampal gyrus, posterior parietal cortex and lateral premotor cortex during home task). Therefore, the authors concluded that the patient retained the ability to respond to language despite being diagnosed with vegetative state (although the possibility remains that this patient may have been minimally conscious and misdiagnosed as vegetative, especially given the high misdiagnosis rate) [58]. Studies like this highlight the ability to evaluate intent, which is a critical component of awareness and represents a different approach than measures that evaluate indicators for information processing (e.g., ERPs) [12].

\section{Minimally Conscious State}

Most of the work on the minimally conscious state has used functional imaging to differentiate it from vegetative state. Boly et al. utilized ${ }^{15} \mathrm{O}$-radiolabeled water positron emission tomography to examine differences between minimally conscious state $(\mathrm{N}=5)$ and vegetative state $(\mathrm{N}=15)$. The patients were tested with a series of auditory 'clicks' approximately one month after being admitted to hospital [59]. The authors found 


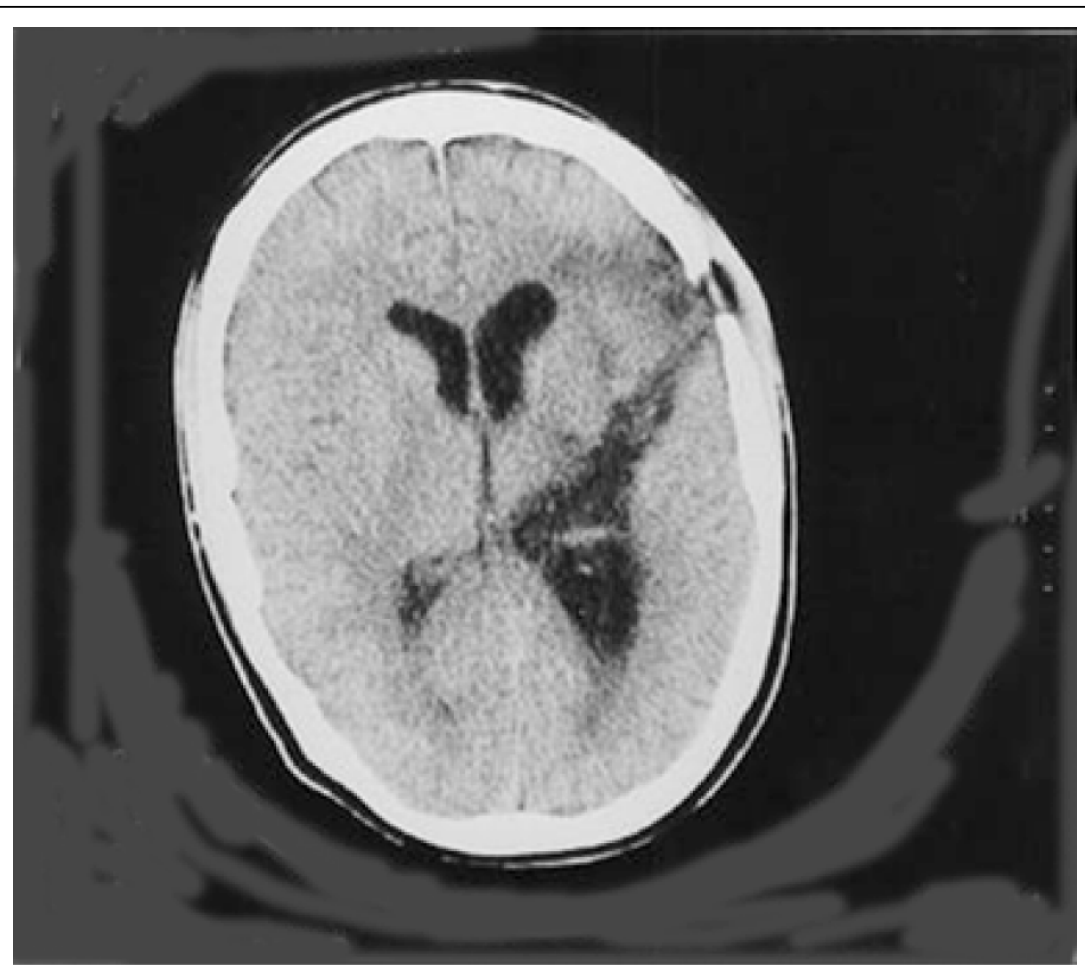

Figure 2 Axial CT scan of a 21 year old male who was stabbed in the left temporal lobe. Scan was taken 4 weeks post-injury and showed no difference from original scans (adapted from Connolly et al., 1999).

widespread activation in the bilateral auditory cortex in minimally conscious state patients compared to vegetative state patients. In addition, minimally conscious state patients demonstrated stronger functional connectivity between secondary auditory cortex and posterior temporal and prefrontal association areas [59]. Di et al. used functional magnetic resonance imaging to study the differential diagnosis between vegetative state $(\mathrm{N}=7)$ and minimally conscious state $(\mathrm{N}=4)$ by presenting the patients own name (spoken by a family member). All of the minimally conscious state patients showed activation in primary and higher order auditory cortex. Interestingly, all but two vegetative state patients showed less activation than minimally conscious state patients, with these two patients subsequently progressing to minimally conscious state within three months. These results provide further support that functional neuroimaging of auditory processing may be used to distinguish different levels of consciousness [60].

\section{Patient}

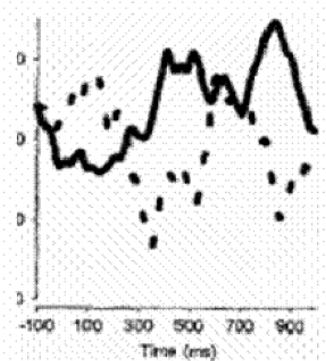

\section{Healthy Control}

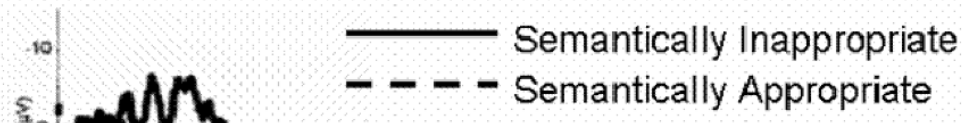

$$
\text { a } 200 \underset{\operatorname{Timo}(\min )}{000} 1000
$$

Figure 3 ERP recordings from a 21 year old patient diagnosed with vegetative state and a matched healthy control. Both the patient and control show an N400 response to semantically inappropriate sentences that were spoken (adapted from Connolly et al., 1999). 


\section{Locked-in Syndrome}

Family members, nurses and therapists are often more likely than physicians to realize that people with locked-in syndrome are conscious [61]. Electrophysiological approaches, such as cognitive ERPs, can diagnose this state at an early time point. Onofrj et al. studied four individuals suspected of having locked-in syndrome using the P300 [62]. The results indicated that a prototypical P300 waveform could be reliably detected in each of these people. The finding of residual cognitive function supported the diagnosis of locked-in syndrome as opposed to vegetative state [62]. The Onofrj et al. study is consistent with the results of other work using cognitive ERPs to evaluate awareness in locked-in syndrome [63].

\section{Limitations}

Electrophysiological assessments of consciousness are quite promising, yet a number of limitations to clinical implementation have been identified. Given that these tools still reside within the research realm, there is limited normative data. In particular, more research needs to be done on the diagnostic/prognostic accuracy of specific components within a test battery [63,64]. In general, electrophysiological and neuroimaging techniques are prone to type II errors rather than type I errors, meaning that such assessments may underestimate cognitive functioning. A potential explanation put forth by Neumann and Kotchoubey is fluctuations in arousal/ alertness [65]; given this, a practical solution may be to assess patients on more than one occasion. There are also technical challenges related to recording reliable, artifact free EEG/ERPs in clinical settings (e.g., noisy environments and ease of implementation). However, advances in both hardware and software are actively being designed and implemented to address these issues. New amplifiers for portable applications exist and methods have been developed for the quantification of waveform data for user-independent clinical use. With the coming advances on all of these fronts, it will be possible to begin assessing the reliability and validity of electrophysiological measures directly within the clinical environment. This represents the critical next step to improving the practical assessment of consciousness.

\section{Conclusions}

Electrophysiological approaches, particularly when combined with functional imaging, can provide objective, clinically relevant assessments of consciousness - even in the presence of concomitant motor and communication problems. The MMN response shows promise in determining prognosis in coma and vegetative state; the MMN and the P300 have diagnostic utility across a range of different levels of awareness. The N400 is particularly useful for indexing high level awareness, such as intact comprehension. When used comprehensively in conjunction with other functional imaging modalities (functional magnetic resonance imaging, positron emission tomography), electrophysiological evaluations have demonstrated value in ascertaining differential diagnosis, residual function, and prognosis. Moreover, cognitive ERPs can be used to evaluate information processing which, in turn, can be used as an indicator of preserved function in brain-injured individuals.

\section{Author details \\ 'Department of Psychology, Dalhousie University, Halifax, Canada. ${ }^{2}$ National Research Council, Institute for Biodiagnostics (Atlantic) Halifax, Canada. ${ }^{3}$ Department of Radiology, Dalhousie University, Halifax, Canada. \\ ${ }^{4}$ Department of Linguistics \& Languages, McMaster University, Hamilton, Canada. ${ }^{5}$ Queen Elizabeth II Health Sciences Centre (Neurology), Halifax, Canada. ${ }^{6}$ Department of Medicine (Neurology), Dalhousie University, Halifax, Canada. ${ }^{7}$ Department of Chemistry, Dalhousie University, Halifax, Canada.}

\section{Authors' contributions}

JRG and RCND were responsible for drafting the manuscript. JFC and DFW critically revised the draft for intellectual content. All authors provided final approval of the version to be published.

\section{Competing interests}

The authors declare that they have no competing interests.

Received: 4 September 2009

Accepted: 29 January 2010 Published: 29 January 2010

\section{References}

1. Zeman A: Consciousness. Brain 2001, 124:1263-1289.

2. Dennett DC: Consciousness explained Boston: Little, Brown 1991.

3. Chalmers DJ: The conscious mind Oxford: Oxford University Press 1996.

4. Baars BJ: A cognitive theory of consciousness Cambridge: Cambridge University Press 1988.

5. Cranford R: Facts, Lies, \& Videotapes: The permanent vegetative state and the sad case of Terri Schiavo. J Law Med Ethics 2005, 33:363-71.

6. Taber $\mathrm{KH}$, Warden DL, Hurley RA: Blast-Related Traumatic Brain Injury: What Is Known?. J Neuropsychiatry Clin Neurosci 2006, 18:141-145.

7. Okie S: Traumatic Brain Injury in the War Zone. N Engl J Med 2005, 352:2043-2047.

8. A report of a working party of the Royal College of Physicians: The vegetative state: guidance on diagnosis and management. Clin Med 2003, 3:249-254.

9. Bateman DE: Neurological assessment of coma. J Neurol Neurosurg Psychiatry 2001, 71:13-17.

10. Laureys S, Owen AM, Schiff ND: Brain function in coma, vegetative state and related disorders. Lancet Neurol 2004, 3:537-546.

11. Jennett B, Plum F: Persistent vegetative state after brain damage. Lancet $1972,1: 734-737$

12. Owen AM, Coleman MR: Functional neuroimaging of the vegetative state. Nat Rev Neurosci 2008, 9:235-243.

13. Kampfl A, Franz G, Aichner F, Pfausler B, Haring HP, Felber S, Luz G, Schocke M, Schutzhard E: The persistent vegetative state after closed head injury: clinical and magnetic resonance imaging findings in 42 patients. J Neurosurg 1998, 88:809-816.

14. Adams JH, Graham Dl, Jennett B: The neuropathology of the vegetative state after an acute brain insult. Brain 2000, 23:1327-1338.

15. Giacino JT, Ashwal S, Childs N, Cranford R, Jennett B, Katz DI, Kelly JP, Rosenberg JG, Whyte J, Zafonte RD, Zasler ND: The minimally conscious state: Definition and diagnostic criteria. Neurology 2002, 58:349-353.

16. Wijdicks EFM: Minimally conscious state vs persistent vegetative state: the case of Terry (Wallis) vs the case of Terri (Schiavo). May Clin Proc 2006, 81:1155-1158.

17. Smith E, Delargy M: Locked-in Syndrome. MRJ 2005, 330:406-409.

18. Plum F, Posner JB: The diagnosis of stupor and coma. New York: Oxford University Press 2007. 
19. Bauby JD: The diving bell and the butterfly: a memoir of life in death New York: Alfred A. Knopf, Inc 1997, See also: Schnabel J (Director), Harwood R (Screenplay): Le Scaphandre et le papillon, 2007.

20. Laureys S, Giacino JT, Schiff ND, Schabus M, Owen AM: How should functional imaging of patients with disorders of consciousness contribute to their clinical rehabilitation needs?. Curr Opin Neurol 2006, 19:520-527.

21. Andrews K, Murphy L, Munday R: Misdiagnosis of the vegetative state: retrospective study in a rehabilitation unit. BMJ 1996, 313:13-16.

22. Schnakers C, Vanhaudenhuyse A, Giacino J, Ventura M, Boly M, Majerus S, Moonen G, Laureys S: Diagnostic accuracy of the vegetative and minimally conscious state: Clinical consensus versus standardized neurobehavioral assessment. BMC Neurology 2009, 9:35.

23. Giacino JT, Smart CM: Recent advances in behavioral assessment of individuals with disorders of consciousness. Curr Opin Neurol 2007, 20:614-619.

24. Fairley D, Timothy J, Donaldson-Hugh M, Stone M, Warren D, Cosgrove J: Using a coma scale to assess patient consciousness levels. Nurs Times 2005, 101:38-41.

25. Rappaport M, Hall KM, Hopkins HK: Disability rating scale for severe head trauma: coma to community. Arch Phys Med Rehabil 1982, 63:118-123.

26. Schiff ND: Multimodal neuroimaging approaches to disorders of consciousness. J Head Trauma Rehabil 2006, 21:388-397.

27. Knight RT: Consciousness Unchained: Ethical Issues and the Vegetative and Minimally Conscious State. The American Journal of Bioethics 2008, $8: 1-2$.

28. Cabeza R, Kingstone A: Handbook of Functional Neuroimaging of Cognition. Boston: MIT Press 2001.

29. Jezzard P, Matthews PM, Smith SM: Functional MRI: an introduction to methods New York: Oxford University Press 2001.

30. Bushberg JT: The essential physics of medical imaging. Philadelphia, USA: Lippincott Williams \& Wilkins, second 2002.

31. Schiff ND, Rodriguez-Morena D, Kamal A, Kim KH, Giacino JT, Plum F, Hirsch J: fMRI reveals large-scale network activation in minimally conscious patients. Neurology 2005, 64:514-523.

32. Staffen W, Kronbichler M, Aichhorn M, Mair A, Ladurner G: Selective brain activity in response to one's own name in the persistent vegetative state. J Neurol Neurosurg Pschiatry 2006, 77:1383-1384.

33. Chiappa $\mathrm{KH}$, Hill RA: Evaluation and prognostication in coma. Electroencephalogr Clin Neurophysiol 1998, 106:149-155.

34. Daltrozzo J, Wioland N, Mutschler V, Kotchoubey B: Predicting coma and other low responsive patients outcome using event-related brain potentials: a meta-analysis. Clin Neurophysiol 2007, 118:606-614.

35. Connolly JF, D'Arcy RC: Innovations in neuropsychological assessment using event-related potentials. Int J Psychophysiol 2000, 37:31-47.

36. Luck SJ: An introduction to the event related potential technique. Cambridge, MA: MIT Press 2005.

37. Polich J: Updating P300: An integrative theory of P3a and P3b. Clin Neurophysiol 2007, 118:2128-2148.

38. Polich J: Clinical application of the P300 event-related brain potential. Phys Med Rehab Clin N Amer 2004, 15:133-161.

39. D'Arcy RC, Connolly JF, Eskes GA: Evaluation of reading comprehension with neuropsychological and event-related brain potential (ERP) methods. J Int Neuropsychol Soc 2000, 6:556-567.

40. Herrmann CS, Knight RT: Mechanisms of human attention: event-related potentials and oscillations. Neurosci Biobehav Rev 2001, 25:465-476.

41. Woods DL: The component structure of the N1 wave of the human auditory evoked potential. Electroencephalogr Clin Neurophysiol Suppl 1995, 44:102-109.

42. Näätänen $R$, Paavilainen $P$, Rinne $T$, Alho $K$ : The mismatch negativity (MMN) in basic research of central auditory processing: a review. Clin Neurophysiol 2007, 18:2544-2590.

43. Kutas M, Hillyard SA: Reading senseless sentences: Brain potentials reflect semantic incongruity. Science 1980, 207:203-205.

44. Friederici AD: Event-related brain potential studies in language. Curr Neurol Neurosci Rep 2004, 4:466-470.

45. Kutas M, Hillyard SA: Reading senseless sentences: brain potentials reflect semantic incongruity. Science 1980, 207:203-205.

46. Van Petten C, Kutas M: Influences of semantic and syntactic context on open- and closed-class words. Mem Cognit 1991, 19:95-11.
47. Connolly JF, Mate-Kole C, Joyce BM: Global Aphasia: An innovative assessment approach. Arch Phys Med Rehabil 1999, 80:1309-1315.

48. D'Arcy RC, Marchand Y, Eskes GA, Harrison ER, Phillips SJ, Major A, Connolly JF: Electrophysiological assessment of language function following stroke. Clin Neurophysiol 2003, 114:662-672.

49. Marchand Y, D'Arcy RC, Connolly JF: Linking neurophysiological and neuropsychological measures for aphasia assessment. Clin Neurophysiol 2002, 113:1715-1722.

50. Fischer C, Morlet D, Giard M: Mismatch negativity and N100 in comatose patients. Audiol Neurootol 2000, 5:192-197.

51. Logi F, Fischer C, Murri L, Maguiere F: The prognostic value of evoked responses from primary somatosensory and auditory cortex in comatose patients. Clin Neurophysiol 2003, 114:1615-1627.

52. Zandbergen EG, de Haan RJ, Stoutenbeek CP, Koelman JH, Hijdra A: Systematic review of early prediction of poor outcome in anoxicischaemic coma. Lancet 1998, 352:1808-1812.

53. Fischer C, Luauté J: Evoked potentials for the prediction of vegetative state in the acute stage of coma. Neuropsychol Rehabil 2005, 15:372-380.

54. Fischer C, Luauté J, Adeleine P, Morlet D: Predictive value of sensory and cognitive evoked potentials for awakening from coma. Neurology 2004, 63:669-673.

55. Daltrozzo J, Wioland N, Mutschler V, Kotchoubey B: Predicting coma and other low responsive patients outcome using event-related brain potentials: A meta-analysis. Clin Neurophysiol 2007, 118:606-614.

56. Fischer C, Dailler F, Morlet D: Novelty P3 elicited by the subject's own name in comatose patients. Clin Neurophysiol 2008, 119:2224-2230.

57. Wijnen VJ, van Boxtel GJ, Eilander HJ, de Gelder B: Mismatch negativity predicts recovery from the vegetative state. Clin Neurophysiol 2007, 118:597-605.

58. Owen AM, Coleman MR, Boly M, Davis MH, Laureys S, Pickard JD: Detecting awareness in the vegetative state. Science 2006, 313:1402

59. Boly M, Faymonville ME, Peigneux $P$, Lambermont B, Damas $P$, Del Fiore $G$, Degueldre C, Franck G, Luxen A, Lamy M, Moonen G, Maquet P, Laureys S: Auditory processing in severely brain injured patients: differences between the minimally conscious state and the persistent vegetative state. Arch Neurol 2004, 61:233-238.

60. Di HB, Yu SM, Weng XC, Laureys S, Yu D, Li JQ, Qin PM, Zhu YH, Zhang SZ, Chen $Y Z$ : Cerebral response to patient's own name in vegetative and minimally conscious states. Neurology 2007, 68:895-899.

61. Laureys S, Pellas F, Van Eeckhout P, Ghorbel S, Schnakers C, Perrin F, Berré J, Faymonville ME, Pantke KH, Damas F, Lamy M, Moonen G, Goldman S: The locked-in syndrome: what is it like to be conscious but paralyzed and voiceless?. Prog Brain Res 2005, 150:495-511.

62. Onofrj M, Thomas A, Paci C, Scesi M, Tombari R: Event related potentials recorded in patients with locked-in syndrome. J Neurol Neurosurg Psychiatry 1997, 63:759-764

63. Perrin F, Schnakers C, Schabus M, Degueldre C, Goldman S, Brédart S, Faymonville ME, Lamy M, Moonen G, Luxen A, Maquet P, Laureys S: Brain response to one's own name in vegetative state, minimally conscious state and locked-in syndrome. Arch Neurol 2006, 63:562-569.

64. Kotchoubey B, Lang S, Mezger G, Schmalohr D, Schneck M, Semmler A, Bostanov $\mathrm{V}$, Birbaumer $\mathrm{N}$ : Information Processing in severe disorders of consciousness: vegetative state and minimally conscious state. Clin Neurophysiol 2005, 116:2441-2453.

65. Neumann N, Kotchoubey B: Assessment of cognitive functions in severely paralysed and severely brain-damaged patients: neuropsychological and electrophysiological methods. Brain Res Brain Res Protoc 2004, 14:25-36.

\section{Pre-publication history}

The pre-publication history for this paper can be accessed here:http://www biomedcentral.com/1471-2377/10/11/prepub

doi:10.1186/1471-2377-10-11

Cite this article as: Gawryluk et al:: Improving the clinical assessment of consciousness with advances in electrophysiological and neuroimaging techniques. BMC Neurology 2010 10:11 